\title{
A Review On Public Health through Rural Health Mission: Pharmacist Roles and Responsibility
}

\author{
Renukaradhya Chitti ${ }^{1 *}$, Rajesh Venkataraman ${ }^{2}$, Jeet Bahadur Moktan ${ }^{3}$, \\ Kumaraswamy $\mathbf{M}^{4}$,
}

Shiv Kumar Yadav ${ }^{5}$, Yogendra Shrestha ${ }^{6}$, B M Dinnimath ${ }^{7}$.Sindhu Shree ${ }^{8}$, Manisha.H.M ${ }^{9}$

1,3,4,5,6,8,9, Research Scholar, \& Pharm D Intern, Department of Pharmacy Practice, Sri Adichunchanagiri College of Pharmacy, Adichunchanagiri University, BG Nagara, Karnataka, India.

${ }^{2}$ Professor \& Head, Department of Pharmacy Practice, Sri Adichunchanagiri College of Pharmacy, Adichunchanagiri University, BG Nagara, Karnataka, India.

${ }^{7}$ Assistant Professor, Department of Pharmaceutical Chemistry, KAHER College of Pharmacy, Hubballi, Karnataka, India.

\section{Corresponding Author:}

Mr. Renukaradhya Chitti

Research Scholar,

Department of Pharmacy Practice,

Sri Adichunchanagiri College of Pharmacy,

Adichunchanagiri University,

BG Nagara, Karnataka, India.

Email: rsc3842@gmail.com.

Mob No: 8884563842. 


\begin{abstract}
:
For many years, the Government of India has worked hard to offer health services to people all around the country, and it remains dedicated to doing so. It has formed numerous programmes to achieve the goal of "Health for All." As a result, in 2005, The Hon'ble Prime Minister formed the The National Rural Health Mission will provide the countries' network with well-being administrations. The National Rural Health Mission, which went into effect in April 2005, is considered the backbone of the rural sector. They have been instilled with the belief that, as a result of their efforts, something special has appeared to assist the country dwellers in re-establishing their well-being. The National Rural Health Mission (NRHM) aims to provide rural populations, especially disadvantaged groups, with comprehensive, low-cost, and high-quality health care.
\end{abstract}

\title{
Material \& Method:
}

We reviewed all of the articles published on PubMed, Scopus, BMJ, Google scholar, Nature, Web of science that were focusing on, National rural health mission services, to achieving universal health coverage (UHC).

Conclusion: This study compiles a list of all social need interventions that have been described in the literature to date. National health systems around the world are reforming to meet health goals, with a focus on cost containment, universal coverage, equity in access and quality, and resource efficiency and effectiveness. The primary purpose of the mission is to establish a fully operational, community-owned, decentralised health-care delivery system with cross-sectoral integration at all levels, enabling for simultaneous action on a wide variety of health determinants such as poverty and social equity.

Key words: NRHM, Rural Health, health care, UHC

\section{Introduction:}

India government have declared their commitment to achieving universal health care (UHC). Despite this, universal health coverage remains a distant objective, and the Indian health-care system remains beset by serious deficiencies in terms of staff, infrastructure, and service quality and availability [1]. In India, primary health care is the backbone of rural health care. Health care's objective is to help individual's live healthier lives. Its holistic existence also attempts to provide preventative, medical, and status services to all with rehabilitative treatment facilities [2]. In three stages, we are currently contemplating and applying these endorsements to promising Indian well-being maintenance: Second, we examine a suggestion screening that is crucial to significant growth. The critical softness in India's health-care system is next classified, and finally, the foundations of India's health-care dilemma are revealed, which can only be corrected by a strong commitment to the planned National Health Assurance Program. Mission which is founded on universal health-care principles [3]. The National Rural Health Mission's (NRHM) public health In India, the criteria are not higher than international standards. Community pharmacies have the potential to significantly improve people's lives [4]. According to previous studies, despite their capabilities, neighbourhood pharmacies are underutilised in the delivery of public healthcare services [5]. Pharmacists at hospitals and health-care systems (health-care pharmacists) perform a critical role. According to the American Society of Health-System Pharmacists (ASHP), all healthcare pharmacists have a responsibility to participate in global, national, state, regional, and institutional efforts to promote public health and to incorporate those efforts' aims into their practises. Pharmacists in health-care systems are also responsible for promoting public health in collaboration with public health planners [6]. 


\section{MATERIAL AND METHOD}

We reviewed all of the articles published on Pub Med, Scopus, BMJ, Google scholar, Nature, Web of science that were focusing on, National rural health mission services, to achieving universal health coverage (UHC).

\section{Health System In India}

The Current Existing Health-Care System can be better understood with a basic understanding of India's health-care system. The World Health Organization defines public health as "the science and art of improving health, preventing disease, and extending life through society's collective efforts [7]. Public health is a social and political ideology that aims to enhance people's health, life expectancy, and quality of life by focusing on disease prevention, health promotion, and other health-related activities [8]. According to the World Health Organization (WHO), a well-functioning health system is based on competent and empowered health workers, a well-maintained health system, and a well-functioning health system that functions in harmony [9]. The ultimate purpose of the health-care system is to improve population health [10]. Outcomes in a fair and equitable manner while avoiding excessive health-care costs [11]. at the attainment of inception, India's health-care system was methodically designed to provide primary, preventative, and curative treatment (1946) includes in remote and rural areas, as well as curative health care at a reasonable distance of the people [12]. India's health-care system currently operates on a three-tiered structure for providing services to its citizens [13]. Many state governments create networks of primary, secondary, and tertiary health-care facilities that offer free or low-cost medical services. Individual physicians and their clinics, as well as general and super-specialty hospitals, make up the private health-care industry. India's Three-tiered Health-Care System is a schematic depicting the country's three-tiered health-care system (ANM: Auxiliary Nurse-Midwife and MPW: Multipurpose Workers) A sort of medical therapy known as primary health care (PHC) is a type of medical treatment. Primary health care is the first point of interaction for individuals and families with the healthcare system [14].

\section{Rural Health Mission Services Application}

In terms of the requirements of the poor and vulnerable in rural communities, the Indian government has worked relentlessly for many years to offer health care to people across the country, and it has implemented a number of programmes to do so. The goal of "Health for All." As a result, in 2005, was established to provide health care in rural areas [15].

NRHM's main goal is to deliver high-quality, low-cost healthcare [16]. Developing a network of Accredited Social Health Activists to deliver accountable, cheap, and dependable primary health care while bridging the rural-urban divide (ASHA). The NRHM's goal is to improve rural healthcare, with a special emphasis on women's and children's needs [17]. The significance of these proposals will be discussed in this section. We summarise evidence showing that, despite some notable gains in health indicators, India's health results fall short of its economic successes; second, we identify basic faults in India's health-care system; and third, we explain the origins of India's health-care crisis, which can only be addressed if it is addressed [18].

Residents of rural areas have access to the same high-quality health-care services as city dwellers. "Universal access to competent, motivated, and supported health workers, particularly in remote and rural communities, is a crucial condition for realising the human right to health, which is also a social justice issue," according to the World Health Organization [19]. Due to low resources, a communist ideology, fragmented health systems, ineffective management, and socioeconomic disparities, providing healthcare and sickness prevention to India's billion-plus people has always been difficult. When it comes to health 
entrepreneurship, the Indian government must recognise its own limitations. India must repeat its successful privatisation track record in medical treatment, health infrastructure supply and maintenance, and people empowerment. Otherwise, its ambitious rural and urban health initiatives will fail, and national health empowerment programmes will fall short. Indian health-care system, and asks that India's health-care planners look into other healthcare growth possibilities. [20]From 2005-06 to 2012-13, India undertook the National Rural Health Mission (NRHM), a multifaceted community-based project aimed at improving $\mathrm{MCH}$ outcomes and reducing disparities in $\mathrm{MCH}$. The mission's purpose was to improve access to and availability of high-quality health care, primarily for the poor in order to minimise socioeconomic inequalities; for rural populations in order to reduce geographic disparities; and for women and children in order to help close gender gaps [21].

The impact of NRHM is restricted since the JSY (Janani Suraksha Yojana) provides money transfers to mothers and ASHAs (Accredited Social Health Activists) in exchange for adopting institutional delivery, but no cash transfer is offered to ASHAs until 2010. There was reduced social diversity in institutional delivery in the early post-NRHM period, but not in ANC use. We divided the post-NRHM period into two halves, based on data availability: early post-NRHM (2007-08) and late post-NRHM (2011-12).It is also expected that, in terms of institutional delivery and ANC (Areas of Natural Constraint) acceptance, the late post-NRHM age of the program's largest outreach will have stronger NRHM equity implications than the early post-NRHM era of the program's largest outreach [22].

Between 2005 and 2013, this report examined the state of health system research in India. The National Rural Health Mission (NRHM) and other government-sponsored initiatives [23].

\section{Karnataka's ASHA programme was evaluated as part of the National Rural Health Mission.}

The Accredited Social Health Activist (ASHA) programme, which began in 2005, is one of the key components of the National Rural Health Mission (NRHM). A multitude of competing narratives about what constitutes meaningful effort adds to the difficulty of judging ASHA [24].

\section{The following are the important NRHM initiatives:}

ASHA (Accredited Social Health Activists): ASHAs (Accredited Social Health Activists) are volunteers who assist in the creation of a link between the health system and the community. More than 8.84 lakh community health volunteers contributed to the success of this programme. ASHA is the initial point of contact for any health-related needs of the poor, particularly women and children who face barriers to health treatment in rural areas. This programme is gaining traction across the country, and it has been shown to be particularly effective in re-engaging people with the public health system. Outpatient services, diagnostic centres, institutional delivery, and inpatient care are all becoming more popular.

\section{Hospital Management/Roga Kalyan Samiti (Patient Welfare Committee)Society:}

A united fund controls funds and other forms of financial aid for these communities interested in patient welfare activities; it is a recognised society that serves as a board of trustees to oversee the hospitals' operations.

United Nations Sub-Centre Grants It has given auxiliary nurse midwives (ANMs) in the field more confidence, as they now have blood pressure monitoring equipment, a stethoscope, and a weighing machine, among other things. They can receive proper prenatal care and other medical procedures. Another important tool for community empowerment is the Village Health, Sanitation, and Nutrition Committee (VHSNC), which operates at the grassroots 
level. Providing Health-Care Services Providing health-care services needs a significant amount of human capital. The country's public health-care system, according to various estimates, is chronically understaffed. The National Rural Health Mission (NRHM) has hired over 1.7 lakh individuals, including 8,871 doctors, 2025 specialists, 76,643 ANMs, 41,609 staff nurses, and others, in an attempt to ease human resource shortages. Mobile Medical Units have been able to reach places that were previously unreachable (MMU). There are a total of 2024 MMUs in 459 districts all around the place The government also offers free ambulance services around the country, which may be called on a toll-free number and arrive within minutes. The National Rural Health Mission has distributed more than 12,000 basic and emergency patient transport vehicles (NRHM).

\section{Janani Shishu Suraksha Karyakram}

The Janani Shishu Suraksha Karyakram (JSSK) initiative was launched by the government to promote universal healthcare by giving free transportation, drugs, diagnostics, blood, and nutrition to pregnant mothers and unwell new-borns who give birth in public health facilities [25].

\section{Health Awareness, health awareness programme, health awareness in India:}

India is a densely populated country with a significant population that does not have access to primary health care or basic education. When opposed to metropolitan areas, the situation in rural villages is more complicated. Their homes are dilapidated, with no running water or electricity [26]. They can collect a small amount of water from remote sources and rarely care about showering, washing their clothes, or improving their living conditions. Aside from their dire socioeconomic situations, a lack of education and public awareness contributes considerably to their agony. The Vivid Foundation organises health awareness programmes on a monthly basis with the help of volunteer doctors who donate their time to the cause. The governments of India have launched a total of 26 public awareness campaigns on health issues. As a sample, fifty graduates were drawn at random from each university were established in order to increase institutional deliveries. The top sources of health-related information for these students at both universities were identified to be television, newspapers, radio, billboards, the Internet, and family members/friends. The survey's most striking finding is that, although 60 percent of Bangladeshi pupils are aware of health activities, only 14 percent of Indian students are. It demonstrates that India's National Rural Health Mission (NRHM) is still in trouble. According to students from both schools, healthawareness initiatives and collaborative efforts to enhance the healthcare system should be developed [27].

\section{Awareness about NRHM Services}

The National Rural Health Mission was known to the vast majority of them. According to 65.7 percent of respondents, the government, health centres, and Ghrama panchayats all implement the National Rural Health Mission's services. The significant majority of respondents (62.8 percent) were aware of the Indian government's rural insurance scheme. The vast majority of them had heard of the Janani Suraksha Yojna (62.2 percent). The Janani Suraksha Yojna, according to 60.5 percent of those polled, was founded to improve institutional delivery. The JSY's mother's financial assistance programme was known to the vast majority of them (64.2 percent). The government had designated an ASHA to provide health services in their region, and the vast majority of them (70 percent) were aware of this. The vast majority (74.8\%) were aware of the ASHA in their area. ASHA visits their houses on a daily basis, according to the vast majority of them (71.8 percent). They believe that a male or female health care practitioner should pay them a visit at their house on a frequent 
basis (68.6 percent).Prenatal screenings and immunizations are free at primary health centres, according to the majority of them ( 85.2 percent). The Sub Centre provided a 24 -hour referral service for severe pregnancy and birth scenarios, according to the majority of them $(68.1$ percent). The significant majority of them $(74.8 \%)$ were aware of the free iron folic acid pill and Tetanus Toxoid supplied during the Antenatal check-up. The PHC, according to 67.4 percent of them, has a 134-bed normal delivery facility that is open 24 hours a day. At the time of referral, 62.5 percent of them were aware that a woman in labour should be accompanied to the proper care facility by an ANM or other trained people. 64.4 percent of them were aware that ORS is available in the Sub Centre and Aanganwadi for diarrhoea and dehydration prevention. 70.1 percent were aware that the Sub Centre offers family planning services such as pill distribution, condom distribution, and Copper-T insertion. Only $75 \%$ of those asked knew the PHC provides tubectomy and vasectomy services. Subcentre/Aanganwadi held regular health and nutrition days, and 63\% were aware of them. The vast majority of them (66.6 percent) were aware that doctors and nurses at Subcentre and primary health centres should be available at all hours of the day and night.62.5 percent of them were aware that the health centre, in collaboration with the Gram Panchyat, is responsible for conducting water quality testing in each village. 64 percent of individuals polled were aware of the Primary Health Centre/Rural Hospital's Child Development Clinic, which treats malnourished children [15].

\section{CONCLUSION}

The National Rural Health Mission's services, were found to be inadequate. Because the majority (43.5 percent) were secondary educated or illiterate, their lack of knowledge of health services might be attributed to a low reading level (21.1 percent). The National Rural Health Mission's services were underutilised due to a lack of awareness among them, as well as the distance between the health centre and their homes, the cost of government health services, a lack of female doctors at health centres to care for female patients, a lack of adequate explanation of disease conditions, and the non-availability of prescribed drugs at health centres. Janani Shishu, Janani Suraksha, Janani Shishu, Janani Suraksha, Janani ShishuYojana, Suraksha Karyakram, the establishment of Sick Newborn Care Units, and universal health care are only a few examples. According to the report, the NRHM's objectives and accomplishments in the state are limited by a lack of community participation, a systematic focus on decentralised planning, and a shortage of professional and educated Public Health staff. Larger studies will be needed in the future to learn more about pharmacists' involvement in patient care and public health in India, as well as how pharmacy education might help them in this endeavour. National health systems around the world are reforming to meet health goals, with a focus on cost containment, universal coverage, equity in access and quality, and resource efficiency and effectiveness.

\section{ACKNOWLEDGMENT}

Nil

\section{CONFLICT OF INTEREST \\ No interest}

\section{REFERENCES}

1. Angell BJ, Prinja S, Gupt A, Jha V, Jan S. The Ayushman Bharat Pradhan Mantri Jan Arogya Yojana and the path to universal health coverage in India: Overcoming the challenges of stewardship and governance. PLoS Med. Vol. 16, no.3, (2019), pp. 
2. Dave DR, Dave R. A study on Service quality and customer satisfaction of selected Private hospitals of Vadodara City. Pacific Business Review International. 2014 May;6(11):7-12.

3. Jamison DT, Summers LH, Alleyne G, et al. Global health 2035: a world converging within a generation. Vol. 12 ,no 3,(2013)pp1898-955.

4. Basak SC, Sathyanarayana D. Community Pharmacy Practice in India: Past, Present and Future. Southern Med Review.Vol.2,no.1,( 2009; 2),pp 11-4.

5. Hermansyah A, Sainsbury E, Krass I. Community pharmacy and emerging public health initiatives in developing $S$ outheast A sian countries: a systematic review. Health \& social care in the community. Vol.24,no.5,(2016 )pp.11-22.

6. Ibrahim JK, Burris S, Hays S. Public health law research: exploring law in public health systems. Journal of Public Health Management and Practice.Vol.18, no.6,(2012) pp.499505.

7. World Health Organization, World Report on Knowledge for Better Health Strengthening Health Systems, Vol.19,No.2,( 2004).pp.

8. World Health Organization. Health Promotion Glossary,vol. 19. No.1,(1998)pp. 138

9. Stenberg K, Hanssen O, Edejer TT, Bertram M, Brindley C, Meshreky A, Rosen JE, Stover J, Verboom P, Sanders R, Soucat A. Financing transformative health systems towards achievement of the health Sustainable Development Goals: a model for projected resource needs in 67 low-income and middle-income countries. The Lancet Global Health. Vol.5,no.9(2017).pp.875-87.

10. World Health Organization Maximizing Positive Synergies Collaborative Group. An assessment of interactions between global health initiatives and country health systems. The Lancet.Vol.373,no.9681,(2009).pp.2137-69.

11. Wijesooriya NS, Rochat RW, Kamb ML, Turlapati P, Temmerman M, Broutet N, Newman LM. Global burden of maternal and congenital syphilis in 2008 and 2012: a health systems modelling study. The Lancet Global Health. Vol.4,no.8,(2016) pp.525-33.

12. Jain K. Health financing and delivery in India: An overview of selected schemes. Women in Informal Employment Globalising and Organising (WIEGO) Working Paper No. Vol.10,no.5, (2013).pp.1-28.

13. Majumder $A$ and Upadhyay $V$. An analysis of the primary health care system in India with focus on reproductive health care services. ArthaBeekshan.Vol.12,no.4, (2004).pp.29-38.

14. Declaration of Alma-Ata, Report of the International Conference on Primary Health Care, vol.12, no.3 (2016)pp,98.

15. Ray SK. Awareness \& Utilization of National Rural Health Mission Ser-vices Among People of Selected Rural Areas in The State of Maharashtra. Natl J Community Med. Vol5, no. 4( 2014)pp.387-91.

16. Venkata SP, Kielgast P, Udhumansha U, Airaksinen M. Role of Pharmacists in National Public Health Programs in India: A Survey on Pharmacy Students' Perceived Knowledge and Attitude. Indian Journal of Pharmaceutical Education and Research.vol.50, no.1( 2016) pp.51-62.

17. Shashank KJ, Angadi MM, Masali KA, Wajantri P, Bhat S, Jose AP. A study to evaluate working profile of accredited social health activist (ASHA) and to assess their knowledge about infant health care. Vol. 5, no. 12(2013) pp.97-103.

18. Sen G. Universal Health Coverage in India: A long and winding road. Economic and Political Weekly. Vol. 25, no.2. (2012), pp.45-52.

19. Douthit N, Kiv S, Dwolatzky T, Biswas S. Exposing some important barriers to health care access in the rural USA. Public health.vol.129, no.6( 2015) pp.611-20. 
20. Naik G L, Deshpande S R.Models Of Health Care Development For Disease Free India. Journal of Clinical and Diagnostic Research [serial online]vol.31, no.4( 2010)pp.123

21. Gupta M, Bosma H, Angeli F, Kaur M, Chakrapani V, Rana M, Van Schayck OC. A mixed methods study on evaluating the performance of a multi-strategy national health program to reduce maternal and child health disparities in Haryana, India. BMC public health.vol.17, no.1, (2017) pp.698.

22. Vellakkal S, Gupta A, Khan Z, Stuckler D, Reeves A, Ebrahim S, Bowling A, Doyle P. Has India's national rural health mission reduced inequities in maternal health services? A pre-post repeated cross-sectional study. Health policy and planning.vol.32,no. 1( 2017) pp.79-90.

23. Rao KD, Arora R, Ghaffar A. Health systems research in the time of health system reform in India: a review. Health research policy and systems.vol.12,no.1,(2014) pp.37.

24. Mony P, Raju M. Evaluation of ASHA programme in Karnataka under the National Rural Health Mission. InBMC proceedings. Vol.6, no.5,( 2012)pp.345.

25. Husain Z, Ghosh S. Is health status of elderly worsening in India? A comparison of successive rounds of national sample survey data. Journal of Biosocial Science. Vol. 43, no.2,(2011)pp. 211-31.

26. Navaneetham $K$, Dharmalingam A. Utilization of maternal health care services in Southern India. Social science \& medicine.vol.55, no.10( 2002) pp.1849-69.

27. Latif S, Rana R, Qadir J, Ali A, Imran MA, Younis MS. Mobile health in the developing world: Review of literature and lessons from a case study. Vol.5, no.1(2017) pp.1154056. 